\title{
IdeAs
}

Idées d'Amériques

$17 \mid 2021$

Villes et culture dans les Amériques

\section{Ariel A. Goldstein, Poder evangélico: cómo los grupos religiosos están copando la política en América}

Buenos Aires, Marea, 2020, 240 pages

\section{Alvar De La Llosa}

\section{CpenEdition}

\section{Journals}

Édition électronique

URL : https://journals.openedition.org/ideas/10414

DOI : $10.4000 /$ ideas. 10414

ISSN : 1950-5701

Éditeur

Institut des Amériques

Référence électronique

Alvar De La Llosa, « Ariel A. Goldstein, Poder evangélico: cómo los grupos religiosos están copando la política en América », IdeAs [En ligne], 17 | 2021, mis en ligne le 01 mars 2021, consulté le 07 juin 2021. URL : http://journals.openedition.org/ideas/10414; DOI : https://doi.org/10.4000/ideas.10414

Ce document a été généré automatiquement le 7 juin 2021.

\section{$(1) \Theta \Theta$}

IdeAs - Idées d'Amériques est mis à disposition selon les termes de la licence Creative Commons Attribution - Pas d'Utilisation Commerciale - Pas de Modification 4.0 International. 


\title{
Ariel A. Goldstein, Poder evangélico: cómo los grupos religiosos están copando la política en América
}

Buenos Aires, Marea, 2020, 240 pages

\author{
Alvar De La Llosa
}

\section{RÉFÉRENCE}

Ariel A. Goldstein, Poder evangélico: cómo los grupos religiosos están copando la política en América, Buenos Aires, Marea, 2020, 240 pages

1 En dix chapitres et un post-scriptum (consacré aux évangéliques face à la pandémie), Ariel Goldstein, docteur en sciences sociales (université de Buenos Aires), observe la croissance du pouvoir des Églises évangéliques et leurs relations avec le monde politique en Amérique latine au cours des trente dernières années. Il montre comment l'extension de ce pouvoir inattendu met en péril la démocratie sous-continentale en tissant des réseaux parmi les élites politiques, financières, les médias, mais aussi, et peut-être surtout, en s'introduisant dans la vie privée des citoyens, en ordonnant des conduites (contraception, avortement, orientation sexuelle, définition de la famille) et en dictant des contenus pédagogiques scolaires. Leurs liens avec le pouvoir leur permettent de recevoir des financements qui échappent au contrôle démocratique.

Reprenant les études de Charles Wright Mills et Irving Horowitz sur la confiscation des décisions transcendantales par une petite élite, Goldstein étudie de façon fouillée ce que l'évangélique brésilien Edir Macedo nomme leur "plan de pouvoir». Ses sources sont la presse britannique, israélienne et des Amériques, des articles de revues de sociologie et les déclarations d'hommes politiques, au total, quatre cent soixante-six notes de références. Certains chapitres sont apparus dans des revues universitaires de sociologie. 
3 Liés au retour à la démocratie des sociétés latino-américaines dans les années 1980 et 1990, les partis politiques évangéliques émergent comme une opposition de droite à une église catholique parfois engagée dans la défense des droits humains face aux dictatures. Ils sont renforcés par le néo-pentecôtisme importé des États-Unis qui exalte des valeurs néolibérales. L'argent n'est plus diabolique mais preuve de l'amour divin. Les fidèles sont des entrepreneurs et les valeurs collectives catholiques font place à la réussite individuelle qui est un exemple de la bonté divine sur le groupe. Réussite et effort individuel deviennent la preuve de la grâce et provoquent le rejet de l'aide étatique. Développant une "esthétique du bonheur" familiale liée à la réussite économique, à l'acquisition de biens prouvant l'inévitable réussite de la famille morale, télévisions et radios évangéliques répandent ce pacte de l'entrepreneur avec dieu.

Utilisant les données du Pew Research Center, Goldstein montre la perte, depuis les années 1970, d'un nombre conséquent de fidèles catholiques au profit des évangéliques qui prolongent le discours conservateur, moralisateur et anticommuniste des années 1960. Dans les milieux populaires, cette croissance serait due à la perception de l'évangélisme comme "l'idéologie du miracle » ou une "théologie de la prospérité » alors que le catholicisme apparaît éloigné des populations. L'arrivée en 2013 du pape Bergoglio a accentué cette perception d'une «Église rouge " alors que l'évangélisme serait un appel direct et personnalisé du Christ envers chacun.

5 Goldstein souligne le rôle joué par Israël, où le gouvernement Netanyahu développe «une idéologie messianique d'extrême-droite» (David Halbfinger), en phase avec l'interprétation biblique des pentecôtistes pour qui Jérusalem est le lieu où aura lieu la grande bataille de l'Armageddon, quand Jésus viendra restaurer son règne. Israël est alors vu comme l'endroit du retour du Messie. Cela impose un calendrier des relations internationales auquel les pays latino-américains doivent adhérer. Élu président, l'acteur Jimmy Morales transfère l'ambassade du Guatemala de Tel Aviv à Jérusalem suite à une conversation avec Netanyahu et à la demande de Ralph Drollinger, membre du White House Bible Study group. En janvier 2020, à Miami, le pasteur hondurien Guillermo Maldonado - qui possède dix églises aux États-Unis et appuie la politique migratoire de Trump en annonçant que les illégaux qui assisteront à son office le jour où Trump s'y rendra ne seront pas déportés - défend le transfert de l'ambassade étasunienne à Jérusalem. Il en va de même des relations entre Israël et Bolsonaro.

6 Au Brésil, la crise économique des années 1990 fut le terreau de l'expansion évangélique, notamment dans le nord. L'intégration de trente-neuf millions de personnes dans la classe moyenne facilite le développement de la «théologie de la prospérité ». Se positionnant en faveur des indigènes et du respect de l'Amazonie, l'église catholique est accusée de "néo-marxisme ». Les cultes d'origine africaine sont dénoncés comme ceux de "sectes démoniaques", violemment persécutés par les narcotrafiquants devenus évangéliques. Depuis 1992, des campagnes d'évangélisation en Afrique, notamment en Angola, où les évangéliques possèdent deux cent trente temples dans vingt-trois des cinquante-cinq pays du continent, sont lancées. Un lobby de parlementaires évangéliques dessine la politique africaine de l'Itamaraty.

7 Campagnes anticorruption lancées en 2014, discrédit de la classe politique et crise économique renforcent la pénétration de l'évangélisme dans les couches populaires et la classe ouvrière; l'entraide évangélique (visites aux prisonniers, crèches, aide alimentaire, moralisme) fit le reste en développant une « sociologie sauvage » qui capte les attentes populaires et prépare l'ascension de Bolsonaro par une narration religieuse 
messianique où les élections deviennent une mission morale rédemptrice guidée par dieu.

8 En vingt ans, les évangéliques sont passés de quarante-six à cent quatre-vingt-quinze députés et huit sénateurs; ce lobby contrôle la commission qui octroie les licences de radiodiffusion et l'exemption fiscale des Églises. Les chèques alimentaires gouvernementaux sont distribués par les évangéliques qui augmentent ainsi leur prosélytisme et défendent la privatisation car la fin de l'étatique serait le seul moyen d'en finir avec la corruption. Face à la puissance des télévangéliques, la gauche est admirative mais impuissante. Leur tactique narrative affirme qu'ils sont le peuple chrétien face à ceux qui promeuvent des « idéologies de genre ", avortement, remise en cause du patriarcat et trafic de drogue. Ils construisent ainsi l'image d'un monde apocalyptique - gouverné par la gauche - dont il convient de sortir immédiatement.

En Colombie, la répression contre les guérillas a diabolisé la gauche. Santos bénéficiant de l'appui international, Uribe récolte celui des évangéliques. D'où un référendum qui rejette les accords de paix. Défense de la famille, antiavortement et refus d'un manuel scolaire d'éducation sexuelle sont au menu. Il s'agit non de comprendre mais d'émouvoir, affirmer que les communistes de la guérilla peuvent gagner les élections. Deux imaginaires sur le pays et la famille s'affrontent. En 2018, les évangéliques uribistes facilitent l'élection de Duque en affirmant que les métayers deviendront propriétaires, que Santos est contre la famille puisqu'il promeut "l'idéologie de genre », et que par les accords de paix, Cuba exporte la révolution communiste.

10 L'évangélisme argentin se nourrit de la misère des bas quartiers, du vide créé par la répression militaire contre les églises de base, des chaînes de télévisions voire des espaces cédés par des chaînes d'État, et, dans les provinces pauvres du nord-ouest, de l'abandon social des vétérans de la guerre de Malouines. Le pacte militaro-religieux est renouvelé par la base. Le spectre d'une émigration vénézuélienne et de ses agents chavistes est convoqué. Des pasteurs étaient en contact avec le dictateur Ríos Montt et son état-major. Otto Pérez Molina qui coordonna la lutte antisubversive devient président du Guatemala en 2011 et offrit le pays au Christ. En 2020, le président Giammattei jure sur la Bible et non sur la Constitution, comme au Paraguay.

11 Alors que l'église catholique nicaraguayenne critique le gouvernement répressif, Ortega se maintient au pouvoir grâce aux liens tissés par son épouse avec les évangéliques. Ils le soutiennent contre la construction de temples et une place de la Bible. Drollinger participe aux célébrations du $40^{\mathrm{e}}$ anniversaire de la révolution sandiniste. 2,5 des 6,3 millions de Salvadoriens (dont 1,6 aux États-Unis) se reconnaissent comme évangéliques. Nayib Bukele, fils de palestinien et ex membre de la guérilla du FMLN, a renié son passé, déclarant ne connaître que Jésus, rejetant l'avortement et défendant le mariage traditionnel. Suite au coup d'État de 2009 contre Zelaya, salué par les évangéliques, Drollinger visite le Honduras qui signe des accords d'investissement et de sécurité avec Israël. Un pasteur participe à la Commission de dépuration de la police et à celle de la transformation du système éducatif. Là encore, transfert d'ambassade à Jérusalem. Démocratie stable, au Costa Rica le jugement de la Cour interaméricaine des Droits humains en faveur du mariage égalitaire tombe en pleine campagne électorale, promouvant les évangéliques.

12 On connaît le cas d'Áñez qui rêvait « d'un pays libéré des rites sataniques indigènes » et du retour de la Bible au palais présidentiel. Au Pérou les pentecôtistes s'allient avec les Fujimori, puis se mobilisent en 2017 contre l'« idéologie de genre» («queremos 
educación, no perversión »). Naît alors une nouvelle droite conservatrice qui lutte contre les « orgies scolaires " et la "pornographie à l'école ». Par le Front Populaire Agraire, 2020 voit l'entrée des évangéliques au Congrès. Fin 2019, Maduro annonce la création d'une université théologique et livre soixante-dix mille hectares de terres agricoles aux évangéliques. Ses discours se réfèrent désormais à dieu. Comme au Nicaragua, les conflits avec l'église catholique le conduisent à s'approcher des évangéliques qui, bien implantés dans les milieux populaires, appuient le gouvernement qui en échange leur offre des financements leur permettant d'élargir leur influence.

13 Selon Goldstein en Amérique latine la laïcité rétrocède. L'évolution de la législation mexicaine depuis 1992-1994 le prouve. Seul en Uruguay, où la tradition laïque persiste, on entend une ministre déclarer que cette " plaie " augmente parce que " nous ne savons pas créer une utopie de l'homme nouveau au xxI siècle ». Les évangéliques apparaissent là où il existe une fracture du tissu social familial et une absence de l'assistance étatique dans des contextes de crise économique, atteignant ceux qui souffrent de pauvreté, violences conjugales, prison, alcoolisme ou drogue. Ils occupent les espaces sociaux abandonnés par l'État, et ont besoin d'obtenir des fonds étatiques pour mener des politiques sociales qui leur permettent ensuite de négocier avec le parti désirant se maintenir au pouvoir, l'appui populaire en échange de la non application de programmes d'éducation et du droit à l'avortement. Ce système de pouvoir religieux autoritaire, hiérarchique et dogmatique est transféré dans le politique, d'où l'affinité des évangéliques avec les régimes autoritaires (Maduro, Fujimori, Trump, Bolsonaro, Áñez, Ortega), et l'appui qu'ils obtiennent auprès des forces de l'ordre.

Ils prétendent défendre des espaces privés familiaux où, supposément, l'État veut s'introduire. Ainsi leur combat leur permet de faire front commun avec des catholiques face à une supposée menace, une attaque d'un mode de vie propre, renouant ainsi avec les stratégies de la Guerre froide, la défense de la civilisation occidentale et chrétienne. Les évangéliques sont un danger pour la démocratie puisqu'ils introduisent en politique la dichotomie bien/mal, l'adversaire est diabolique (donc à éliminer) et le dirigeant empreint d'une mission divine, détruisant la cohésion. La morale serait donc le lien nécessaire pour réunir autoritarisme et néolibéralisme. Les mobilisations populaires démocratiques étant détournées alors que la précarisation du travail augmente, Goldstein pense que, loin d'être un phénomène passager, l'évangélisme perdurera audelà des figures politiques qui aujourd'hui l'incarnent. Il appartient à l'État de reprendre la main et d'élargir ses politiques sociales vers les secteurs les plus déshérités de la société.

Un ouvrage qui, indubitablement, met en garde contre le pouvoir subreptice de toute religion, et qui s'inscrit dans l'avenir politique. 


\section{AUTEURS}

ALVAR DE LA LLOSA

Université Lyon 2, LCE, EA 1853 